Undas Vol 12. , Nomor 1, Juni $2016: 35--48$

\title{
PEMAKNAAN SIMBOL DALAM MITOS ASAL-USUL NAMA BANJARMASIN SEBUAH ANALISIS STRUKTURALISME LEVI STRAUSS
}

\author{
Symbol Meaning In Myth “Asal-Usul Nama Banjarmasin" A Levi Strauss Structuralisme \\ Analysis
}

Agus Yulianto

Balai Bahasa Kalimantan Selatan

Jalan Jenderal Ahmad Yani Km 32,2, Loktabat, Banjarbaru 70712 Kalimantan Selatan

Telepon (0511) 4772641, Pos-el: agusb.indo@gmail.com

\begin{abstract}
Abstrak: Tujuan Penelitian ini adalah untuk mengetahui makna-makna simbol yang terdapat dalam mitos Asal-usul Nama Banjarmasin sehingga cerita tersebut dapat lebih terpahami oleh pembaca. Dengan demikian masalah dalam penelitian ini adalah apakah makna yang terkandung dalam simbol-simbol yang terdapat dalam cerita mitos Asal-usul Nama Banjarmasin. Kajian ini menggunakan metode deskriptif-kualitatif dengan teknik studi pustaka. Pendekatan yang digunakan dalam penelitian ini adalah pendekatan strukturalisme Levi Strauss. Berdasarkan kajian dapat diketahui bahwa dalam cerita mitos Asal-usul Nama Banjarmasin banyak mengandung simbolsimbol antara lain penggantian nama Bandar Masih atau Banjar Masih menjadi Banjarmasin merupakan simbol yang bermakna nama sebuah daerah terkadang terikat dengan fenomena alam di sekitarnya. Hal itu juga menunjukkan kearifan lokal dari masyarakat setempat.
\end{abstract}

Kata kunci: Makna, mitos, Levi Strauss.

Abstract: The aim of this study is to find out symbol meaning in myth "Asal-usul Nama Banjarmasin" so that this story could be more understandable by the readers. The problem in this study is what are the meaning in the symbols of "Asal-usul Nama Banjarmasin". This study uses descriptive-cualitatif method trough library research. This study also uses structuralism approach by Levi Strauss. Base on the study it is found out that myth in the story of Banjarmasin's nama certain lots of symbols, one of them is the changing name of Bandar Masih or Banjar Masih becomes Banjarmasin. This changing is a symbol which mean the place has a connection with a native phenomenon. It also shows local wisdom of this society.

Key words: The meaning, myth, Levi Strauss

\section{PENDAHULUAN}

Cerita yang terdapat pada zaman dahulu ada di dunia ini yaitu berupa dongengdongeng dianggap sebagai mitos. Mitos tersebut sangat berpengaruh bagi kehidupan manusia. Selain itu, juga mengandung pesan yang sangat bermanfaat, seperti cerita Malin Kundang yang mengisahkan seorang anak yang durhaka kepada ibunya kemudian dikutuk menjadi batu. Cerita tersebut memberi pesan kepada generasi muda untuk tidak mendurhakai orang tuanya. (Lutfitasari,2011:1) Van Peursen mengartikan mitos sebagai sebuah cerita yang memberikan pedoman ke arah tertentu bagi sekelompok orang. Cerita dapat dituturkan, tetapi juga dapat diungkapkan melalui tarian-tarian atau pementasan wayang. Mitos memberikan arah kepada kelakuan manusia, hal ini merupakan semacam pedoman untuk kebijaksanaan manusia (Peursen, 1976:37). 
Menurut Bascom (dalam Danandjaja 2002:58) pada umumnya mitos adalah mengisahkan tentang terjadinya alam semesta, dunia, manusia pertama, bentuk khas binatang, bentuk topografi, gejala alam dan sebagainya. Mitos juga mengisahkan petualangan para dewa, kisah percintaan, hubungan kekerabatan mereka, kisah perang mereka dan lain sebagainya. Mitos biasanya juga menceritakan terjadinya susunan para dewa, dunia dewata, terjadinya manusia pertama dan tokoh pembawa kebudayaan, terjadinya makanan pokok seperti beras untuk pertama kali. Mitos biasanya berkaitan erat dengan kejadian. Kejadian berupa fenomena keanehan alam nyata dan alam ghaib dalam hubungannya dengan manusia. Masyarakat mengakui bahwa mitos itu benar adanya. Mitos sangat dipercaya masyarakat untuk membatasi segala tingkah lakunya. Tingkah laku tersebut ditentukan oleh mitos yang dipercaya masyarakat, sehingga mitos ada yang terangkat sebagai pedoman tingkah laku kelompok masyarakat tertentu dan menjadi cermin bagi kehidupannya.

Menurut Ahimsa (2006:92) dalam konteks Strukturalisme Levi-Strauss dikatakan bahwa, mitos bukan lagi dongeng sebagai pengantar tidur, tetapi merupakan kisah yang memuat sejumlah pesan. Pesanpesan ini tidak tersimpan dalam sebuah mitos yang tunggal, melainkan dalam keseluruhan mitos. Si pengirim pesan dalam mitos tersebut tidak jelas, walaupun dalam mitos tersebut terdapat pesan. Hal ini diasumsikan bahwa si pengirim pesan dalam mitos adalah orang dari generasi terdahulu, dan penerimanya adalah generasi sekarang. Jadi disitu terdapat adanya komunikasi yang bersifat satu arah.

Salah satu kisah mitos yang terkenal di Kalimantan Selatan adalah Kisah Asal-usul Nama Banjarmasin yang terdapat dalam buku Cerita Rakyat dari Kalimantan Selatan karangan H. Yustan Azddin tahun 2013. Banjarmasin adalah ibu kota Provinsi Kalimantan Selatan. Keberadaan kota Banjarmasin tidak terlepas dari tokoh yang sangat terkenal di Kalimantan Selatan, yaitu Pangeran Samudra. Pangeran Samudra adalah raja pertama di Kalimantan Selatan yang memeluk Islam. Setelah beragama Islam, Pangeran Samudra berganti nama menjadi Sultan Surinsyah.

Kisah Pangeran Samudra yang sangat fenomenal saat ini mulai banyak dilupakan orang seiring dengan makin merebaknya genre sastra modern seperti novel, cerpen dan drama. Oleh sebab itu penggalian cerita terhadap Kisah Asal-usul Nama Banjarmasin sangat diperlukan sebagai salah satu upaya pelestarian dari cerita rakyat itu sendiri. Selain itu, penganalisisan cerita dengan menggunakan pendekatan strukturalisme Levi Strauss terhadap cerita mitos Kisah Asal-usul Nama Banjarmasin ini diharapkan membuat cerita mitos tersebut dapat lebih dipahami dan lebih bermanfaat bagi pembaca.

\section{KERANGKA TEORI}

Cerita rakyat (folktale) adalah sejenis cerita prosa yang tergolong fiksi, bisa didasarkan pada suatu kejadian nyata bisa juga rekaan, dan tidak terlalu serius sifatnya. Dalam cerita rakyat tidak ada gambaran tentang waktu maupun tempat tertentu. Meskipun demikian, cerita-cerita rakyat memiliki fungsi penting, misalnya sebagai sarana ajaran moral.

$$
\text { Bascom dalam Danandjaja }
$$
(2002:5) menjelaskan bahwa mitos (myth) adalah sejenis cerita prosa yang dipercaya kebenar $\neg$ annya 
oleh masyarakat pendukung cerita itu. Mitos sebenarnya merupakan pengejawantahan dogma sehingga sifatnya sakral, dan seringkali dihubungkan dengan ritus dan teologi. Mitos menjadi semacam jawaban bagi berbagai persoalan eksistensial pada saat manusia tidak mengerti, bimbang, ataupun kehilangan orientasi. Para pelaku mitos umumnya bukan manusia tetapi memiliki sifat-sifat manusia (misalnya binatang, dewa, ataupun pahlawan budaya). Kejadiannya ditempatkan pada jaman purbakala, pada awal mula dunia ketika dunia belum dimengerti seperti keadaannya yang sekarang, atau dapat terjadi di sebuah dunia lain. Mitos biasanya mengungkap awal mula dunia, awal mula manusia, kematian, atau menjelaskan etiologis binatang, kekhasan geografis, dan fenomena-fenomena alam lainnya. Menurut Wellek dan Warren (1995:243) mitos diartikan sebagai cerita-cerita anonim mengenai asal mula alam semesta dan nasib serta tujuan hidup. Penjelasan-penjelasan yang diberikan oleh suatu masyarakat kepada anak-anak mereka mengenai dunia, tingkah laku manusia, citra alam, dan tujuan hidup manusia.

Menurut Bascom (dalam Danandjaya, 2002:50) mitos pada umumnya mengisahkan terjadinya alam semesta, dunia, manusia pertama, terjadinya maut, bentuk khas binatang, bentuk topografi, gejala alam dan sebagainya.

Menurut Dhanu

berkaitan dengan model analisis struktural Levi-Strauss, pemakaiannya dalam penelitian didasarkan atas asumsi-asumsi bahwa (1) cerita mitos mengandung makna-makna tertentu, dan (2) sebagai fenomena bermakna, cerita mitos baru dapat dipahami makna dan pesannya jika di dalamnya diketahui struktur dan makna berbagai elemennya (lihat Putra, 1995:3-4). Pada (1) cerita mitos dipahami sebagai "mimpi kolektif". Sebagai "mimpi kolektif", cerita mitos pun perlu dianalisis agar dapat diungkapkan makna-makna kolektifnya.

Dengan diungkapkannya makna kolektif di dalam cerita mitos maka akan diketahui pula persoalan-persoalan sosial di dalam cerita mitos tersebut. Pada (2) cerita mitos dipahami sebagai fenomena kebahasaan. Oleh karena itu, relasi antarelemen di dalam struktur cerita mitos harus dianalisis sebagaimana fenomena kebahasaan. Menurut Troubestkoy (Levi-Strauss, 1963:33) analisis struktur dalam linguistik (kebahasaan) mengikuti empat langkah dasar, yaitu (1) linguistik struktural tidak lagi mempelajari gejala bahasa pada tingkat yang disadari (concious linguistic phenomena) tetapi berpindah ke infrastruktur yang berada di bawah sadar (unconcious infrastructure); (2) cara analisis struktural tidak lagi memperlakukan istilah-istilah (terms) sebagai satu-satuan yang berdiri sendiri tetapi memandangnya dalam hubunganhubungan dengan satuan-satuan 
Pemaknaan Simbol dalam Mitos Asal-Usul Nama Banjarmasin Sebuah Analisis Strukturalisme Levi Strauss (Agus Yulianto)

yang lain, dan hubungan antaristilah inilah yang dijadikan titik pangkal analisis; (3) linguistik struktural menggunakan konsep sistem karena dalam ilmu fonemik modern, fonem-fonem tidak hanya dianggap sebagian dari suatu sistem saja, bahkan ilmu tersebut mampu menunjukkan sistem fonemik yang nyata dan membentangkan strukturnya;

linguistik struktural juga bertujuan mengungkapkan dalil-dalil umum, baik melalui induksi maupun deduksi logis, dan dari sana dalildalil tersebut akan memperoleh sifat absolutnya.

Perhatian Levi-Strauss terhadap hubungan antarunsur tadi juga tidak dapat dipisahkan dari konsepnya mengenai struktur sosial, yang merupakan salah satu konsep pokoknya yang harus diketahui jika ingin memahami analisis-analisisnya. Selanjutnya diterangkan, bagi Levi-Strauss, struktur sosial tidak ada hubungannya sama sekali dengan kenyataan empiris. Maksudnya, struktural di sini adalah modelmodel yang dibuat oleh ahli antropologi (dalam penelitian ini harap diartikan: penganalisis cerita mitos yang menjadi objek penelitian) berdasarkan atas kenyataan yang dilihatnya, yaitu hubungan-hubungan sosial yang tampak, yang dapat diamati.

Menurut Levi-Strauss (dalam Dhanu,2015: 5) struktur mitos dapat dijelaskan dengan menunjuk fungsinya, yakni sebagai media untuk mengembangkan suatu argumen logis dalam bentuk preposisi-preposisi. Lewat cara ini, mitos dianggap dapat membantu memecahkan atau "menjelaskan" berbagai kontradiksi yang ada dalam berbagai kepercayaan yang dianut oleh suatu masyarakat. Kontradiksi ini "dirasakan" oleh suatu kelompok atau suatu masyarakat pada tingkat nirsadar. Dalam kaitan ini, cerita mitos dipandang sebagai sebuah perwujudan dari upaya kognitif orang Jawa (Banyuwangi) pada tingkat nirsadar, untuk memecahkan dan memindahkan kontradiksi yang tidak dapat mereka pecahkan pada satu bidang (empiris) ke bidang yang lain (kognitif), sehingga kontradiksi tersebut tampak dapat diantarai, yang pada gilirannya dapat dipecahkan. Oleh karena itu, cerita mitos dapat dipandang sebagai "jendela" untuk melihat kondisi batin masyarakat pendukungnya (Banyuwangi) (lihat Putra, 1995:45). Langkah analisis struktural Levi-Strauss sebagai berikut.

1. Harus diperhatikan keseluruhan episode dalam cerita untuk menafsirkan cerita mitos.

2. Harus didapatkan unit-unit yang ada dalam cerita, yang oleh Putra disebut ceritheme.

3. Ceritheme itu kemudian disusun mengikuti sumbu sintagmatis dan paradigmatis.

4. Dengan mengikuti sumbu sintagmatis dan paradigmatis akan ditemukan relasi antarceritheme, baik yang sama ataupun tidak sama.

5. Interpretasi atas makna cerita bergantung 
pada keseluruhan relasi antarceritheme yang berhasil diperoleh, serta makna referensial maupun konstekstual dari elemen-elemen yang ada dalam ceritheme tersebut.

\section{METODE PENELITIAN}

Metode yang digunakan dalam penelitian ini adalah metode deskriptif kualitatif. Menurut Semi (1990: 105), metode adalah suatu prosedur untuk mencapai suatu tujuan yang telah ditetapkan, sedangkan metode deskriptif menurut Furchan (1982: 440) adalah suatu metode untuk memperoleh informasi tentang kondisi yang ada pada suatu penelitian dilakukan dengan melukiskan kondisi "apa yang ada” itu.

Metode kualitatif memberi ruang kepada peneliti untuk terlibat langsung dengan objek yang diteliti sebagai pengamat dan pemberi interpretasi. Metode kualitatif mengutamakan kedalaman penghayataan terhadap interaksi antara konsep-konsep yang sedang diteliti.

Semi berpendapat (1990: 105) bahwa teknik adalah cara khas yang digunakan atau dilalui dalam mencapai tujuan yang telah ditetapkan dan dengan berpegang pada proses sistematis yang terdapat dalam metode. Teknik penelitian yang digunakan dalam penelitian ini adalah teknik studi pustaka. Teknik studi pustaka digunakan untuk mencari data berupa informasi dari buku-buku yang dianggap relevan dengan penelitian yang dilakukan. Buku tersebut dapat diperoleh dari perpustakaan atau koleksi pribadi.

\section{ANALISIS DAN PEMBAHASAN}

Analisis mitos Asal-usul Nama Banjarmasin dengan pendekatan strukturalisme Levi Strauss dimulai dengan membuat satuan-satuan naratif cerita yang dinamakan ceriteme. Adapun ceriteme-ceriteme yang terdapat dalam cerita sebagai berikut.

(1) Pada zaman dahulu berdirilah sebuah kerajaan bernama Nagara Daha. Kerajaan itu didirikan Putri Kalungsu bersama putranya, Raden Sari Kaburangan alias Sekar Sungsang yang bergelar Panji Agung Maharaja Sari Kaburangan. Konon, Sekar Sungsang seorang penganut Syiwa. Ia mendirikan candi dan lingga terbesar di Kalimantan Selatan. Candi yang didirikan itu bernama Candi Laras.

(2) Pengganti Sekar Sungsang adalah Maharaja Sukamara. Pada masa pemerintahannya, pergolakan berlangsung terus-menerus. Walaupun Maharaja Sukamara mengamanatkan agar cucunya, Pangeran Samudera, kelak menggantikan tahta. Akan tetapi, Pangeran Mangkubumilah yang naik takhta.

(3) Kerajaan tidak hentinya mengalami kekacauan karena perebutan kekuasaan. Konon, siapa pun menduduki takhta akan merasa tidak aman dari rongrongan. Pangeran Mangkubumi akhirnya terbunuh dalam usaha perebutan kekuasaan. Sejak itu, Pangeran Tumenggung menjadi penguasa kerajaan.

(4) Pewaris kerajaan yang sah, Pangeran Samudera pasti tidak aman jika tetap tinggal dalam lingkungan 
kerajaan. Atas bantuan patih Kerajaan Nagara Daha, Pangeran Samudera melarikan diri. Ia menyamar sebagai nelayan dan hidup di daerah sepi di sekitar muara Sungai Barito. Dari Muara Bahan, bandar utama Nagara Daha, mengikuti aliran sungai hingga ke muara Sungai Barito, terdapat kampung-kampung yang berbanjarbanjar atau berderet-deret melintasi tepi-tepi sungai. Kampung-kampung itu adalah Balandean, Sarapat, Muhur, Tamban, Kuin, Balitung, dan Banjar.

(5) Di antara kampung-kampung itu, Banjar-lah yang paling bagus letaknya. Kampung Banjar dibentuk oleh lima aliran sungai yang muaranya bertemu di Sungai Kuin.

(6) Karena letaknya yang bagus, kampung Banjar kemudian berkembang menjadi Bandar, kota perdagangan yang ramai dikunjungi kapal-kapal dagang dari berbagai negeri. Bandar itu di bawah kekuasaan seorang patih yang biasa disebut Patih Masih. Bandar itu juga dikenal dengan nama Bandar Masih.

(7) Patih Masih mengetahui bahwa Pangeran Samudera, pemegang hak atas Nagara Daha yang sah, ada di wilayahnya. Kemudian, ia mengajak Patih Balit, Patih Muhur, Patih Balitung, dan Patih Kuin untuk berunding. Mereka sepakat mencari Pangeran Samudera di tempat persembunyiannya untuk dinobatkan menjadi raja, memenuhi wasiat Maharaja Sukamara.

(8) Dengan diangkatnya Pangeran Samudera menjadi raja dan Bandar Masih sebagai pusat kerajaan sekaligus bandar perdagangan, semakin terdesaklah kedudukan Pangeran Tumenggung. Apalagi para patih tidak mengakuinya lagi sebagai raja yang sah. Mereka pun tidak rela menyerahkan upeti kepada Pangeran Tumenggung di Nagara Daha.

(9) Pangeran Tumenggung tidak tinggal diam menghadapi keadaan itu. Tentara dan armada diturunkannya ke Sungai Barito sehingga terjadilah pertempuran besar-besaran. Peperangan berlanjut terus, belum ada kepastian pihak mana yang menang.

(10) Patih menyarankan kepada Pangeran Samudera agar minta bantuan ke Demak. Konon menurut Patih Masih, saat itu Demak menjadi penakluk kerajaan-kerajaan yang ada di Jawa dan menjadi kerajaan terkuat setelah Majapahit.

(11) Pangeran Samudera pun mengirim Patih Balit ke Demak. Demak setuju memberikan bantuan, asalkan Pangeran Samudera setuju dengan syarat yang mereka ajukan, yaitu mau memeluk agama Islam. Pangeran Samudera bersedia menerima syarat itu.

(12) Kemudian, sebuah armada besar pun pergi menyerang pusat Kerajaan Nagara Daha. Armada besar itu terdiri atas tentara Demak dan sekutunya dari seluruh Kalimantan, yang membantu Pangeran Samudera dan para patih pendukungnya.

(13) Kontak senjata pertama terjadi di Sangi. Pangeran Tumenggung berhasil dipukul mundur dan bertahan di muara Sungai Amandit dan Alai. 
(14) Korban berjatuhan di kedua belah pihak. Panji-panji Pangeran Samudera, Tatungkul Wulung Wanara Putih, semakin banyak berkibar di tempat-tempat taklukannya.

(15) Hati Arya Terenggana, Patih Nagara Daha, sedih melihat demikian banyak korban rakyat jelata dari kedua belah pihak. Ia mengusulkan kepada Pangeran Tumenggung suatu cara untuk mempercepat selesainya peperangan, yakni melalui perang tanding atau duel antara kedua raja yang bertikai. Cara itu diusulkan untuk menghindari semakin banyaknya korban di kedua pihak. Pihak yang kalah harus mengakui kedaulatan pihak yang menang.

(16) Usul Arya Terenggana ini diterima oleh kedua belah pihak.

(17) Pangeran Tumenggung dan Pangeran Samudera naik sebuah perahu yang disebut talangkasan. Kedua pangeran itu memakai pakaian perang serta membawa parang, sumpitan, keris, dan perisai atau telabang. Mereka saling berhadapan di Sungai Parit Basar. Pangeran Tumenggung dengan nafsu angkaranya ingin membunuh Pangeran Samudera. Sebaliknya, Pangeran Samuderatidak tega berkelahi melawan pamannya. Pangeran Samudera mempersilakan pamannya untuk membunuhnya. Ia rela mati di tangan orang tua yang pada dasarnya tetap diakui sebangai pamannya.

(18) Akhirnya, luluh juga hati Pangeran Tumenggung. Kesadarannya muncul. Ia mampu menatap
Pangeran Samudera bukan sebagai musuh, tetapi sebagai keponakannya yang di dalam tubuhnya mengalir darahnya sendiri. Pangeran Tumenggung melemparkan senjatanya. Kemudian, Pangeran Samudera dipeluk. Mereka bertangis-tangisan.

(19) Dengan hati tulus, Pangeran Tumenggung menyerahkan kekuasaan kepada Pangeran Samudera. Artinya, Nagara Daha ada di tangan Pangeran Samudera.

(20) Akan tetapi, Pangeran Samudera bertekad menjadikan Bandar Masih atau Banjar Masih sebagai pusat pemerintahan sebab bandar itu telah berkembang menjadi kota perdagangan. Tidak hanya itu, rakyat Nagara Daha pun dibawa ke Bandar Masih atau Banjar Masih.

(21) Pangeran Tumenggung diberi daerah kekuasaan di Batang Alai dengan seribu orang penduduk sebagai rakyatnya. Nagara Daha pun menjadi daerah kosong.

(22) Sebagai seorang raja yang beragama Islam, Pangeran Samudera mengubah namanya Sultan Suriansyah. Hari kemerdekaan Pangeran Samudera atau Sultan Suriansyah, 24 September 1526, dijadikan hari jadi kota Banjar Masih atau Bandar Masih.

(23) Karena setiap kemarau landang (panjang) air menjadi masin (asin), lama-kelamaan nama Bandar Masih atau Banjar Masih menjadi Banjarmasin.

(24) Akhirnya, Sultan Suriansyah pun meninggal. Makamnya sampai sekarang terpelihara dengan baik dan ramai dikunjungi orang. 
Letaknya di Kuin Utara, di pinggir Sungai Kuin, Kecamatan Banjar Utara, Kota Banjarmasin.

(25) Setiap 24 September Walikota Banjarmasin dan para pejabat berziarah ke makam itu untuk memperingati kemenangan Sultan Suriansyah atas Pangeran Tumenggung. Sultan Suriansyah adalah sultan atau raja Banjar pertama yang beragama Islam.

Berdasarkan teks (ceriteme) yang disajikan mengenai Asal-usul Nama Banjarmasin analisis struktural akan didasarkan pada episode-episode yang disusun oleh peneliti. Adapun analisisnya sebagai berikut.

\section{a. Episode I}

Episode I (paragraph 1) memaparkan tentang asal mula berdirinya kerajaan Nagara Daha. Kerajaan Nagara Daha didirikan oleh Putri Kalungsu dan putranya yang bernama Raden Sekar Kaburangan alias Sekar Sungsang. Sekar Sungsang kemudian mendirikan candi yang bernama Candi Laras. Keberadaan sebuah candi merupakan simbol yang mengandung makna kebesaran seorang raja atau dinasti. Hal itu juga menunjukkan bila raja tersebut merupakan seorang raja yang religious. Oleh sebab itu, dapat dipastikan bila Sekar Sungsang adalah seorang penganut HinduSyiwa yang taat.

\section{b. Episode II}

Episode II (paragraph 2 - 3) memaparkan tentang pergolakan terus menerus yang terjadi di
Kerajaan Nagara Daha. Pada masa pemerintahan Maharaja Sukarama pergolakan terjadi secara terusmenerus. Hal itu merupakan simbol yang mengandung makna bahwa wibawa raja dan kerajaan sudah menurun di mata rakyatnya. Bahkan wasiat raja yang menyatakan Pangeran Samudralah yang kelak akan menggantikan sebagai raja juga tidak diindahkan. Justru Pangeran Mangkubumilah yang merupakan paman Pangeran Samudra yang menjadi raja. Perebutan kekuasaan mencapai puncaknya pada saat Raja Mangkubumi terbunuh dalam pusaran kekuasaan tersebut. Perebuatan kekuasaan yang terjadi di Kerajaan Nagara Daha merupakan simbol yang mengandung makna tahta dan harta masih merupakan sebab yang kuat yang dapat menghancurkan seseorang bahkan kerajaan. Kekuasaan masih dapat menjadi magnet bagi manusia untuk melakukan apa saja demi mendapatkannya. Hal itu disebabkan dengan kekuasaan itulah seseorang merasa akan mendapatkan kemuliaan, harta, bahkan wanita. Padahal kekuasaan adalah sebuah perkara yang sangat berat perhitungan dan petanggungjawabannya. Setelah Raja Mangkubumi terbunuh, Pangeran Tumenggung menjadi raja di Kerajaan Nagara Daha.

\section{c. Episode III \\ Episode III (paragraf 4--6) memaparkan tentang pelarian}


Pangeran Samudra dari Kerajaan Nagara Daha ke Banjar. Pangeran Samudra melarikan diri dari Kerajaan Nagara Daha karena merasa keselamatan masih terancam. Hal itu disebabkan pewaris tahta yang sah sesuai dengan penunjukan Maharaja Sukarama (episode 2) adalah Pangeran Samudra. Pangeran Samudra melarikan diri ke muara Sungai Barito. Di muara Sungai Barito terdapat kampung yang berbanjar-banjar atau berderetderet di tepi sungai. Kampungkampung itu adalah Balandean, Sarapat, Muhur, Tamban, Kuin, Balitung, dan Banjar. Di antara kampung-kampung itu, Banjar-lah yang paling bagus letaknya. Kampung Banjar dibentuk oleh lima aliran sungai yang muaranya bertemu di Sungai Kuin. Karena letaknya yang bagus, kampung Banjar kemudian berkembang menjadi Bandar, kota perdagangan yang ramai dikunjungi kapal-kapal dagang dari berbagai negeri. Bandar itu di bawah kekuasaan seorang patih yang biasa disebut Patih Masih. Bandar itu juga dikenal dengan nama Bandar Masih. Kampung Banjar yang berkembang menjadi Bandar disebabkan dibentuk oleh lima aliran sungai yang muaranya bertemu di Sungai Kuin merupakan simbol yang mengandung makna bahwa sebuah daerah akan menjadi pusat perdagangan atau perniagaan bila akses atau sarana trasportasi menuju daerah tersebut mudah dilalui atau mudah didapat.
Pangeran Samudra menyamar menjadi seorang nelayan ketika berada di muara Sungai Barito. Penyamaran Pangeran Samudra ini merupakan simbol yang mengandung makna bahwa Pangeran Samudra masih merasa keselamatannya terancam. Hal itu karena Aria Tumenggung tetap ingin membunuhnya. Selain itu, hal tersebut juga bermakna kultur asli orang Banjar dari dahulunya adalah berbasis pengairan (sungai). Oleh sebab itulah pangeran Samudra menyamar menjadi seorang nelayan bukan sebagai petani atau yang lainnya.

\section{d. Episode IV}

Episode IV (paragraf $7 \quad-\quad 8$ ) memaparkan tentang penobatan Pangeran Samudra sebagai raja di Bandarmasih. Patih Masih yang mengetahui bahwa Pangeran Samudra adalah pewaris yang sah terhadap tahta kerajaan kemudian mengajak Patih Balit, Patih Muhur, Patih Balitung, dan Patih Kuin menobatkannya menjadi raja. Sikap para Patih ini merupakan simbol yang mengandung makna bahwa para Patih tersebut adalah orangorang yang berpandangan benar. Mereka sadar bahwa pemilik sah tahta Kerajaan Nagara Daha adalah Pangeran Samudra bukan Aria Temenggung. Oleh sebab itu, tidak heran bila para patih di muara Barito menjadikan Pangeran Samudra sebagai raja di sana atas persetujuan rakyat. Selain itu, pengangkatan Pangeran Samudra sebagai raja di muara Barito dengan begitu saja merupakan simbol yang mencerminkan sistem kemasyarakatan 
pada waktu itu, yaitu adanya pengaruh kultur yang kuat dari agama Hindu yang masih dianut pada waktu itu. Para patih dan rakyatnya sadar bahwa Pangeran Samudra adalah seorang raja yang sah. Raja dalam pemahaman masyarakat pada waktu itu adalah titisan dewa. Sabda raja adalah sabda dewa atau Tuhan. Darah raja berbeda dengan dengan darah orang pada umumnya dan kasta raja juga berbeda dengan kasta masyarakat biasa.

\section{e. Episode V}

Episode V (paragraph 9) memaparkan tentang pertempuran yang terjadi antara Pangeran Temenggung dengan Pangeran Samudra. Pertempuran yang terjadi antara pihak Pangeran Temenggung dengan Pangeran Samudra ini sebenarnya merupakan pertempuran antara saudara, yaitu antara paman dan kemenakan. Hal itu merupakan simbol yang mengandung makna bahwa kekuasaan dapat membuat seseorang menjadi hilang akal pikirannya. Sesama saudara dapat saling menumpahkan darah, saling bunuh membunuh. Hilang rasa kasih sayang, rasa mencintai sesama saudara hanya demi kekuasaan semata.

\section{f. Episode VI}

Episode VI (paragraf 10 -- 11 ) memaparkan tentang bantuan Kerajaan Demak kepada pihak Pangeran Samudra. Pihak Pangeran Samudra mulai terdesak oleh pasukan Pangeran Tumenggung. Lama-kelamaan pihak Pangeran Samudra pasti kalah. Oleh sebab itu, para patih menyarankan untuk meminta bantuan kepada Kerajaan Demak. Pangeran Samudra menyetujui usul patihnya itu. Sikap Pangeran Samudra ini merupakan simbol yang mengandung makna bahwa perlawanan perang yang dilakukan oleh Pangeran Samudra adalah perlawanan yang penuh perhitungan dan pantang menyerah. Pada titik ini dapat diketahui konsep "Waja sampai Kaputing" tidak dipahami secara membabi buta, ibarat laron yang menyerbu api yang pasti akan menemui kematian. Pangeran Samudra dapat mengetahui dan mengukur kemampuan pasukan tempurnya yang bila dipaksakan pasti akan kalah. Oleh sebab itu, pangeran Samudra menyetujui usul untuk meminta bantuan ke Demak.

Kerajaan Demak bersedia membantu pihak Pangeran Samudra dengan syarat apabila memenangi pertempuran, Pangeran Samudra dan pengikutnya masuk Islam. Pangeran Samudra menyetujui syarat tersebut. Syarat ini secara merupakan simbol yang mengandung dua makna. Pertama, penyebaran agama Islam tidak dilakukan dengan paksa. Pada kasus ini kerajaan Demak tidak memaksa pangeran Samudra untuk menerima bantuan Demak. Pihak pangeran Samudralah yang bersedia atas syarat tersebut. Kedua, masuknya agama Islam di Kalimantan Selatan dapat dipastikan sangat bersifat patriakhi, yaitu bila seorang pemimpin masuk Islam dapat dipastikan para pengikutnya pun akan masuk Islam. 


\section{g. Episode VII}

Episode VII (paragraf 12 -- 14) memaparkan tentang pertempuran antara Pangeran Temenggung dengan Pangeran Samudra yang mendapat bantuan Demak. Pertempuran terus berlangsung. Akan tetapi, pasukan Pangeran Temunggung banyak mengalami kekalahan. Hal itu disebabkan pasukan Pangeran Samudra sudah mendapat bantuan dari Demak. Panji-panji Pangeran Samudera, Tatungkul Wulung Wanara Putih, semakin banyak berkibar di tempattempat taklukannya. Hal itu merupakan simbol bila kemenangan pasukan Pangeran Samudra sudah dekat.

\section{h. Episode VIII}

Episode VIII (paragraf 15 -- 17) memaparkan tentang usul dari Patih Nagara Daha agar pertempuran hanya diadakan antara Pangeran Samudra dengan Pangeran Temunggung saja agar korban yang berjatuhan tidak semakin banyak. Usul Arya Trenggana agar Pangeran Samudra dan Pangeran berduel satu lawan satu merupakan simbol yang mengandung makna kebijaksanaan pemikiran. Hal itu disebabkan penyelesaian peperangan menjadi semakin mudah dan korban menjadi sedikit. Akan tetapi, terdapat kejadian yang mengejutkan, yaitu Pangeran Samudra malah bersedia menyerahkan nyawa karena tidak tega untuk melawan pamannya sendiri. Tindakan Pangeran Samudra ini merupakan simbol yang mengandung makna ketulusan, kasih sayang, cinta, dan rasa hormat terhadap saudara tuanya yang merupakan pamannya.

\section{i. Episode IX}

Episode IX (paragraf 18 -- 19 ) memaparkan tentang kesadaran Pangeran Temenggung terhadap kesalahannya. Pada saat Pangeran Samudra menyerahkan nyawanya, hati Pangeran Temenggung menjadi luluh dan menyadari kesalahannya bahwa Pangeran Samudra adalah orang yang memiliki hak terhadap kerajaan Nagara Daha dan segera menyerahkannya kepada Pangeran Samudra. Kesadaran yang menghampiri Pangeran Temenggung merupakan simbol bahwa hati manusia akan luluh bila didekati dengan hati. Hati yang tulus, ikhlas, cinta, sayang akan menggema dan menggetarkan hati yang lain. Boleh dikatakan bahhwa Pangeran Temenggung adalah orang yang masih memiliki hati.

\section{j. Episode $X$}

Episode X (paragraf 20-21) memaparkan tentang pangeran Samudra yang tidak mau kembali ke Nagara Daha dan memilih untuk menetap di Bandar Masih. Sikap Pangeran Samudra ini merupakan simbol dari pemahamannya yang ingin mengakhiri konflik yang berkepanjangan. Oleh sebab itu, Pangeran Temenggung tetap diberi kekuasaan sebagai bentuk penghormatan dan legitimasi kekuasaan. 
Pemaknaan Simbol dalam Mitos Asal-Usul Nama Banjarmasin Sebuah Analisis Strukturalisme Levi Strauss (Agus Yulianto)

\section{k. Episode XI}

Episode XI (paragraf 22) memaparkan tentang pengubahan nama Pangeran Samudra. Setelah memeluk agama Islam Pangeran Samudra berganti nama menjadi Sultan Suriansyah. Pergantian nama dan gelar raja tersebut merupakan simbol yang mengandung makna adanya penguatan identitas sebagai seorang muslim. Oleh sebab itu, Pangeran Samudra ingin lebih mengedepankan dirinya sebagai seorang muslim. Salah satu caranya adalah dengan mengubah nama dan gelar sebagai seorang raja yang lebih mengedepankan keidentitasan seorang muslim.

\section{Episode XII}

Episode XII (paragraf 23) memaparkan tentang asal-usul nama Banjarmasin. Banjarmasin pada mulanya bernama Banjarmasih atau Bandarmasih. Karena setiap kemarau landang (panjang) air menjadi masin (asin), lama-kelamaan nama Bandar Masih atau Banjar Masih menjadi Banjarmasin. Hal itu merupakan simbol bahwa nama sebuah daerah terkadang terikat dengan fenomena alam di sekitarnya. Hal itu menunjukkan kearifan lokal dari masyarakat setempat.

\section{m. Episode XIII}

Episode XIII (paragraf 24-25) memaparkan tentang meninggalnya Sultan Suriansyah. Sultan suariansyah akhirnya meninggal dunia. Sampai saat ini pun makamnya banyak diziarahi orang. Hal itu merupakan simbol yang bermakna Sultan Suriansyah diakui sebagai tokoh besar yang banyak berjasa kepada masyarakat Banjar. Terutama dengan keislaman yang dipilihnya. Pilihan Sultan Suriansyah untuk masuk Islam menyebabkan jutaan orang pengikutnya juga masuk Islam.

\section{PENUTUP}

Cerita yang terdapat pada zaman dahulu ada di dunia ini yaitu berupa dongeng-dongeng dianggap sebagai mitos. Salah satunya adalah mitos Asalusul Nama Banjarmasin. Kisah mitos ini tidak dapat dilepaskan dari kisah perjuangan Pangeran Samudra dalam perebutan tahta yang sangat berdarah di Kerajaan Nagara Daha.

Mitos Asal-usul Nama Banjarmasin juga banyak mengandung simbolsimbol yang memerlukan pemaknaan. Simbol-simbol tersebut antara lain:

Pelarian Pangeran Samudra dari Nagara Daha ke daerah muara Sungai Barito menjadi titik tolak perjuangan sang pangeran. Perkenalan Pangeran Samudra dengan para Patih muara Sungai Barito membuat perjuangannya melawan Pangeran Tumenggung menjadi sebuah keniscayaan. Kalah jumlah dan pengalaman berperang membuat pihak Pangeran Samudra memutuskan untuk meminta bantuan Demak. Demak sendiri bersedia membantu perjuangan Pangeran Samudra dengan syarat apabila pihak Pangeran Samudra memenangi pertempuran maka ia beserta seluruh pasukannya harus masuk Islam. Syarat tersebut disetujuai oleh Pangeran Samudra. Syarat ini secara merupakan simbol yang mengandung dua makna. Pertama, penyebaran agama Islam tidak dilakukan dengan paksa. 
Pada kasus ini kerajaan Demak tidak memaksa pangeran Samudra untuk menerima bantuan Demak. Pihak pangeran Samudralah yang bersedia atas syarat tersebut. Kedua, masuknya agama Islam di Kalimantan Selatan dapat dipastikan bersifat patriakhal, yaitu apabila seorang pemimpin masuk Islam dapat dipastikan para pengikutnya juga akan masuk Islam.

Penyelesaian perang yang terjadi antara pihak Pangeraan Samudra dan Pangeran Temenggung adalah melalui jalan tanding satu lawan satu. Akan tetapi, hasilnya sungguh di luar dugaan. Pangeran Samudra malah bersedia menyerahkan nyawa karena tidak tega untuk melawan pamannya sendiri. Tindakan Pangeran Samudra ini merupakan simbol yang mengandung makna ketulusan, kasih sayang, cinta, dan rasa hormat terhadap saudara tuanya yang merupakan pamannya. Pada saat Pangeran Samudra menyerahkan nyawanya, hati Pangeran Temenggung menjadi luluh dan menyadari kesalahannya bahwa Pangeran Samudra adalah orang yang memiliki hak terhadap kerajaan Nagara Daha dan segera menyerahkannya kepada Pangeran Samudra. Kesadaran yang menghampiri Pangeran Temenggung merupakan simbol bahwa hati manusia akan luluh bila didekati dengan hati. Hati yang tulus, ikhlas, cinta, sayang akan menggema dan menggetarkan hati yang lain. Boleh dikatakan bahhwa Pangeran Temenggung adalah orang yang masih memiliki hati.

Nama Kota Banjarmasin pada mulanya bernama Banjarmasih atau Bandarmasih. Karena setiap kemarau landang (panjang) air menjadi masin (asin), lama-kelamaan nama Bandar Masih atau Banjar Masih menjadi Banjarmasin. Hal itu merupakan simbolisasi bahwa nama sebuah daerah terkadang terikat dengan fenomena alam di sekitarnya. Hal itu juga menunjukkan kearifan lokal dari masyarakat setempat.

\section{DAFTAR PUSTAKA}

Ahimsa Putra, Heddy Shri. 2006. Strukturalisme Levi Strauss Mitos dan Karya Sastra. Yogyakarta: KEPPEL PRESS.

Aziddin, Yustan H. 2013. Cerita Rakyat dari Kalimantan Selatan. Jakarta: PT Gramedia Widiasarana.

Dananjaja, James.2002. Folklore Indonesia: Ilmu Gosip, Dongeng dan lain-lain. Jakarta: Grafiti.

Furchan, Arief. 1982. Pengantar Penelitian dalam Pendidikan. Surabaya: Usaha Nasional.

Levi Strauss, C. 1963. Structural Antropology. New York: The University of Chicago Press. 
Pemaknaan Simbol dalam Mitos Asal-Usul Nama Banjarmasin Sebuah Analisis Strukturalisme Levi Strauss (Agus Yulianto)

Lutfitasari, Defiana.2011. Mitos Cerita Candi Gamelan di Kabupaten Pekalongan (skripsi). Semarang: Universitas Negeri Semarang, Fakultan Bahasa dan Seni.

Peursen, Van. 1976. Strategi Kebudayaan. Yogyakarta. Kanisius.

Priyo Prabowo Dhanu.2015. Makna Mitos Asal Nama Kota Banyuwangi Sebuah Analisis Strukturalisme Levi Strauss (makalah). Yogyakarta: Balai Bahasa Yogyakarta.

Semi. M. Atar. 1988. Anatomi Sastra. Padang: Angkasa.

Wellek, Renne dan Austi Warren. 1990. Teori Kesusastraan. Jakarta: Gramedia. 